\title{
A new perspective on concepts of asthma severity and control
}

\author{
D.R. Taylor, E.D. Bateman, L-P. Boulet, H.A. Boushey, W.W. Busse, T.B. Casale, \\ P. Chanez, P.L. Enright, P.G. Gibson, J.C. de Jongste, H.A.M. Kerstjens, \\ S.C. Lazarus, M.L. Levy, P.M. O’Byrne, M.R. Partridge, I.D. Pavord, M.R. Sears, \\ P.J. Sterk, S.W. Stoloff, S.J. Szefler, S.D. Sullivan, M.D. Thomas, \\ S.E. Wenzel and H.K. Reddel
}

ABSTRACT: Concepts of asthma severity and control are important in the evaluation of patients and their response to treatment but the terminology is not standardised and the terms are often used interchangeably. This review, arising from the work of an American Thoracic Society/European Respiratory Society Task Force, identifies the need for separate concepts of control and severity, describes their evolution in asthma guidelines and provides a framework for understanding the relationship between current concepts of asthma phenotype, severity and control.

"Asthma control" refers to the extent to which the manifestations of asthma have been reduced or removed by treatment. Its assessment should incorporate the dual components of current clinical control (e.g. symptoms, reliever use and lung function) and future risk (e.g. exacerbations and lung function decline).

The most clinically useful concept of asthma severity is based on the intensity of treatment required to achieve good asthma control, i.e. severity is assessed during treatment. Severe asthma is defined as the requirement for (not necessarily just prescription or use of) highintensity treatment. Asthma severity may be influenced by the underlying disease activity and by the patient's phenotype, both of which may be further described using pathological and physiological markers. These markers can also act as surrogate measures for future risk.

KEYWORDS: Asthma, control, definitions, severity

or most diseases, basic therapeutic principles dictate that treatment should be based on establishing a working diagnosis followed by an initial assessment of severity, in order to provide a guide to the intensity of therapy that will be needed. Thereafter, for chronic diseases, treatment decisions are usually based on whether control of the disease processes and their clinical manifestations has been achieved. In clinical trials, study populations are usually selected on the basis of a firm diagnosis and the presence of clinical or pathophysiological features that establish the fact that patients have the potential to improve.

The situation is more complex for asthma, a heterogeneous syndrome whose natural history is characterised by variability in its symptoms and signs over time. The definition of asthma [1, 2] includes two domains (symptoms and variable airway obstruction) that are readily amenable to being assessed by clinicians, and two additional domains (airway inflammation and airway hyperresponsiveness (AHR)) that characterise the underlying disease process but are less accessible in clinical practice. However, with the present definition of asthma, none of these domains is "both necessary and sufficient" for the diagnosis, i.e. although features of all four domains are characteristic of populations with diagnosed asthma, an individual patient may have features of any or all of them. In primary care, where most asthma is managed, the diagnosis of asthma is often based only on symptoms (wheeze, cough, shortness of breath and chest tightness). However, these symptoms are not specific to asthma and they overlap considerably with other respiratory conditions, such as chronic obstructive pulmonary disease, or with nonrespiratory conditions, such as cardiac failure or obesity. Given the difficulties of assessing AHR and airway inflammation in primary care, these domains of asthma are often
AFFILIATIONS

For affiliations, see the

Acknowledgements section.

CORRESPONDENCE

D.R. Taylor

Dunedin School of Medicine

University of Otago

P0 Box 913

Dunedin

New Zealand

Fax: 6434747641

E-mail: robin.taylor@

stonebow.otago.ac.nz

Received:

November 192007

Accepted after revision:

March 282008

STATEMENT OF INTEREST

Statements of interest for D.R. Taylor,

E.D. Bateman, L-P. Boulet,

H.A. Boushey, W.W. Busse,

T.B. Casale, P. Chanez, P.L. Enright,

P.G. Gibson, J.C. de Jongste,

M.L. Levy, P.M. O'Byrne, M.R.

Partridge, I.D. Pavord, M.R. Sears,

P.J. Sterk, S.W. Stoloff, S.D. Sullivan,

S.J. Szefler, M.D. Thomas,

S.E. Wenzel and H.K. Reddel can be found at www.erj.ersjournals.com/

misc/statements.shtml 
not assessed even at initial presentation, and lung function is often not measured. As a result, clinicians have little opportunity to become familiar with their relative contribution in patients with a diagnosis of asthma.

The clinical usefulness of these measures is also affected by the rate at which they change over time, not only in relation to the environment and the underlying disease process, but also in response to treatment. Symptoms and lung function may change rapidly from day to day or even hour to hour (e.g. with allergen exposure) and can respond rapidly to initiation of treatment, whereas airway responsiveness tends to change relatively slowly with treatment. Similarly, pathophysiology may change with time, e.g. with the development of airway wall remodelling and relatively fixed airway obstruction.

As a result, even in patients with well-characterised asthma, the relationship between the underlying disease processes and their clinical manifestations is not strong. All of these issues pose challenges regarding how patients with asthma should be diagnosed and assessed, and how treatment response should be judged. In clinical trials, an expanding array of clinical and pathophysiological outcome measures has been used to evaluate asthma control. However, there has been no agreement to date on the relative importance or weight of any of these measures.

Against this background, in 2004, the European Respiratory Society and the American Thoracic Society jointly established a Task Force to provide recommendations about standardised measures for assessing asthma control, severity and exacerbations, primarily in the context of clinical trials. These recommendations will be published in due course. The Task Force commenced by investigating existing usage of the terms "asthma control" and "asthma severity" in clinical trial publications from 1990 to 2004. Many papers described baseline status and/or treatment outcomes in terms of asthma severity, assessed on the basis of symptoms, reliever use, lung function and exacerbations, with reference to international guidelines [1, 3]. However, many other publications described baseline status and/or treatment outcomes in terms of asthma control, referencing the same guidelines and using the same outcome variables and cut points. The synonymous use of these terms reflects the fact that severity and control have never been adequately defined or standardised. The present manuscript identifies the need for separate concepts of severity and control, describes the evolution of these concepts and provides a framework for understanding their relationship.

\section{HISTORICAL PERSPECTIVE}

The easier of the two concepts to define is asthma control. In lay usage, "control" conveys the sense of being reined in or kept within certain boundaries. This concept translates readily to asthma. There is no known cure for asthma, but it is controllable in the majority of patients. Over the past $15 \mathrm{yrs}$, there has been general agreement that a patient's level of asthma control represents the extent to which the clinical manifestations of asthma have been removed or reduced by treatment. In 1996, COCKCROFT and SWYSTUN [4] highlighted the fact that the goals of asthma treatment coincide with ideal asthma control, namely absent/minimal symptoms, minimal/ no requirement for rescue $\beta_{2}$-agonist, no night-time or early morning symptoms, normal lifestyle, minimal airway obstruction and no morbidity [5]. International guidelines consistently describe the goals of asthma treatment as relating not only to the control of patients' current symptoms, but also to the prevention of future adverse outcomes, such as exacerbations, a rapid decline in lung function and side-effects of treatment $[2,6]$. Therefore, the assessment of asthma control falls into two broad categories: assessment of the current level of clinical control: and assessment of future risk to the patient. These dual components have been particularly emphasised in the recently published Expert Panel Report (EPR)3 of the National Heart, Lung, and Blood Institute [6] in terms of "current impairment" and "future risk".

While earlier guidelines described ideal asthma control, the 2006 Global Initiative for Asthma (GINA) guidelines [2] provided a working schema to formalise the classification of asthma control. This categorises asthma as follows. "Controlled": the patient has symptoms and reliever use twice per week or less, no night waking, no activity limitation or airway obstruction, and no exacerbations; "partly controlled": symptoms or reliever use are present more than twice per week, any night waking, activity limitation or airway obstruction, or an exacerbation in any week; and "uncontrolled": the presence of any three or more of these individual features within any week. This classification was consensus-based, and has not yet been validated. The guidelines directly link this classification of asthma control to decisions about asthma treatment, with a recommendation that treatment should be stepped up if asthma is uncontrolled, and that a stepup should be considered if asthma is partly controlled. This approach represents a major shift from the previous approach of basing treatment decisions on asthma severity.

The concept of asthma severity itself has evolved substantially over the years. Discussion about severity is complicated by the widespread use of the word to refer to the intensity or magnitude of individual features, e.g. severity of airway obstruction, or of individual events, e.g. severity of an exacerbation (table 1). However, the present discussion relates to the concept of overall asthma severity. In the 1995 GINA guidelines [3], overall asthma severity was assessed primarily on the basis of the patient's clinical characteristics prior to commencing treatment. Off-treatment severity was categorised into intermittent, mild persistent, moderate persistent and severe persistent, based on symptoms, reliever use, night waking and peak expiratory flow (PEF) or the per cent predicted forced expiratory volume in one second. This initial severity classification was then used to determine the patient's initial treatment. A similar classification was published in the 1997 National Asthma Education and Prevention Program 2 guidelines (table 2) [1] and the 2002 GINA guidelines [7]. The current authors' literature search indicated that these classification tables were rarely used as intended, with many publications using them to delineate the severity of asthma in patients who were already on treatment. This confusion is not surprising, as the clinical features used in the classification of asthma severity off treatment were essentially the same as those described in the same guidelines for assessing asthma control in patients on treatment.

In order to deal with the assessment of patients on treatment, the 1995 GINA guidelines [3] introduced the concept of the 


\begin{tabular}{|c|c|c|}
\hline $\begin{array}{l}\text { Common us } \\
\text { features }\end{array}$ & age of the terms "severity" and "control" in asthma & a, indicating both the overlapping and the distinguishing \\
\hline \multirow[t]{2}{*}{ Characteristic } & \multicolumn{2}{|c|}{ Common usage of the terms } \\
\hline & "Severity" & “Control” \\
\hline Symptoms & $\begin{array}{c}\text { The intensity of respiratory distress when asthma symptoms/ } \\
\text { episodes/attacks occur }\end{array}$ & $\begin{array}{l}\text { The frequency with which symptoms, episodes and attacks } \\
\text { occur over time }\end{array}$ \\
\hline Medication & $\begin{array}{l}\text { Amount of treatment required to maintain best symptom } \\
\text { control and lung function }\end{array}$ & $\begin{array}{l}\text { Frequency with which additional therapy is required, } \\
\text { especially SABA use and courses of steroid tablets }\end{array}$ \\
\hline Lung function & The degree of loss of lung function & $\begin{array}{l}\text { The variability of change in lung function which occurs over a short to } \\
\text { medium time frame }\end{array}$ \\
\hline
\end{tabular}

medication required to maintain control. This was further developed by COCKCROFT and SWYSTUN [4], who, highlighting the potential for over-treatment, based their classification of severity on down-titration to establish the minimum treatment required to maintain control (table 3). These approaches allowed for assessment of severity during treatment and recognised that asthma control could be more difficult to achieve in some patients than in others. However, it was not widely recognised that the COCKCROFT and SWYSTUN [4] categorisation of mild, moderate and severe asthma was only applicable to patients whose symptoms were well controlled on each of the specified levels of treatment. Any patient whose symptoms were not well controlled on the highest treatment level (high or very high dose inhaled corticosteroids (ICS) with or without oral corticosteroids) was classified as very severe. The utility of this classification was limited by the need to formally determine a patient's minimum

TABLE 2 Previous classification system for asthma severity

\begin{tabular}{|c|c|c|c|}
\hline & \multicolumn{3}{|c|}{ Clinical features before treatment ${ }^{\#}$} \\
\hline & Symptoms & Night-time symptoms & Lung function \\
\hline \multirow[t]{3}{*}{ Step 4: severe persistent } & Continual symptoms & Frequent & FEV 1 or PEF $\leqslant 60 \%$ pred \\
\hline & Limited physical activity & & PEF variability $>30 \%$ \\
\hline & Frequent exacerbations & & \\
\hline \multirow[t]{4}{*}{ Step 3: moderate persistent } & Daily symptoms & More than once per week & FEV 1 or $\mathrm{PEF}>60$ and $\leqslant 80 \%$ pred \\
\hline & Daily use of inhaled SABA & & PEF variability $>30 \%$ \\
\hline & Exacerbations affect activity & & \\
\hline & Exacerbations more than twice per week; may last days & & \\
\hline \multirow[t]{2}{*}{ Step 2: mild persistent } & $\begin{array}{l}\text { Symptoms more than twice per week but no more than } \\
\text { once per day }\end{array}$ & More than twice per month & FEV 1 or $P E F \geqslant 80 \%$ pred \\
\hline & Exacerbations may affect activity & & PEF variability $20-30 \%$ \\
\hline \multirow[t]{3}{*}{ Step 1: mild intermittent } & Symptoms no more than twice per week & $\begin{array}{l}\text { No more than twice } \\
\text { per month }\end{array}$ & FEV 1 or $P E F \geqslant 80 \%$ pred \\
\hline & Asymptomatic and normal PEF between exacerbations & & PEF variability $<20 \%$ \\
\hline & $\begin{array}{l}\text { Exacerbations are brief (from a few hours to a few days); } \\
\text { intensity may vary }\end{array}$ & & \\
\hline
\end{tabular}

From the National Asthma Education and Prevention Program Expert Panel Report 2 [1]. Asthma severity was classified by clinical characteristics before treatment. FEV1: forced expiratory volume in one second; PEF: peak expiratory flow; \% pred: \% predicted; SABA: short-acting $\beta_{2}$-agonist. ${ }^{\#}$ : the presence of one of the features of severity is enough to place the patient in that category. An individual should be assigned to the most severe grade in which any feature occurs. The characteristics noted are general and may overlap because asthma is highly variable. Furthermore, an individual's classification may change over time. ': Patients at any level can have mild, moderate or severe exacerbations. Some patients with intermittent asthma experience severe and life-threatening exacerbations separated by long periods of normal lung function and no symptoms. 


\begin{tabular}{|c|c|c|}
\hline Asthma severity & Symptoms & Treatment requirements \\
\hline Very mild & Mild/infrequent (synonym well controlled) & None or rare $\beta$-agonist \\
\hline Mild & Well controlled & $\beta_{2}$-agonist (occasional) \pm low-dose ICS \\
\hline Moderate & Well controlled & $\begin{array}{c}\text { Moderate- to high-dose ICS } \pm \text { occasional } \\
\text { ingested corticosteroid }\end{array}$ \\
\hline Severe & Well controlled & High- to very high-dose ICS \pm ingested corticosteroid \\
\hline Very severe & Not well controlled & $\begin{array}{l}\text { Very high-dose ICS and ingested corticosteroid } \\
\qquad \pm \text { additional therapies }\end{array}$ \\
\hline
\end{tabular}

ICS: inhaled corticosteroids. Reproduced from [4], with permission from the publisher.

effective treatment [8]. In addition, it is not necessarily possible, or even desirable, to use very high doses of ICS or regular oral corticosteroids in all patients who fail to achieve optimal control on lower doses. Therefore, such patients were unable to be classified under this system.

An expanded approach to defining severity was taken in the 2002 GINA guidelines (table 4) [7]. The initial assessment of severity (and hence the starting treatment step) was decided off-treatment, as before, but for subsequent reassessment on treatment, the patient's severity classification was increased by one level (i.e. to a worse severity) for every increased step in current treatment. For example, patients with clinical features of mild persistent asthma were classified as having moderate persistent asthma if they were taking step 2 treatment (lowdose ICS), and as severe persistent asthma if they were taking step 3 treatment (low- or moderate-dose ICS and long-acting $\beta$ agonist (LABA)). In this model, worsening severity was defined by worsening clinical control and/or increasing treatment requirements, i.e. by any movement to the right or downwards in the table (table 4). Although this concept appropriately allowed for differences in level of clinical control

\section{TABLE 4 Previous classification system for asthma from Global Initiative for Asthma (GINA) 2002 [7]}

\section{Patient symptoms and lung function}

Current treatment step

\begin{tabular}{ccc}
\hline Step 1: intermittent & $\begin{array}{c}\text { Step 2: mild } \\
\text { persistent }\end{array}$ & $\begin{array}{c}\text { Step 3: moderate } \\
\text { persistent }\end{array}$ \\
\hline Intermittent & Mild persistent & Moderate persistent
\end{tabular}

Step 1: intermittent

Symptoms less than once per week

Brief exacerbations

Nocturnal symptoms no more than twice per month

Normal lung function between episodes

Step 2: mild persistent

Symptoms more than once per week but less than once per day

Nocturnal symptoms more than twice per month but less

than once per week

Normal lung function between episodes

Step 3: moderate persistent

Symptoms daily

Exacerbations may affect activity and sleep

Nocturnal symptoms at least once per week

$\mathrm{FEV}_{1}>60$ and $<80 \%$ pred or PEF $>60$ and $<80 \%$ of personal best

Step 4: severe persistent

Symptoms daily

Frequent exacerbations

Frequent nocturnal asthma symptoms

FEV $1 \leqslant 60 \%$ pred or PEF $\leqslant 60 \%$ of personal best
The patient's severity classification was increased (worsened) by one step for each increased step in treatment. Any change towards the right or towards the bottom of the table represented worsening severity. Treatments are as defined in [7]. FEV1: forced expiratory volume in one second; \% pred: \% predicted; PEF: peak expiratory flow. 


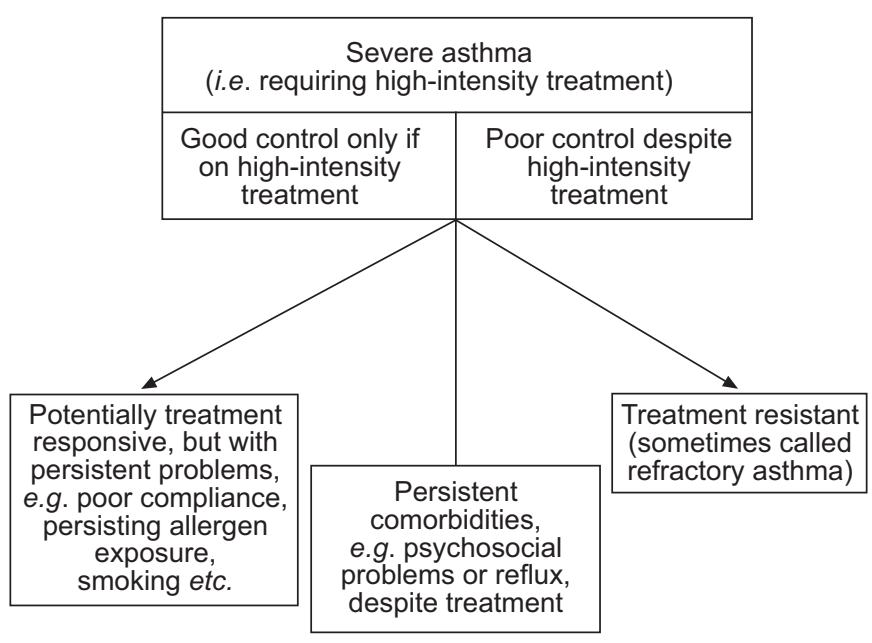

FIGURE 1. Severe asthma is now defined as the requirement for (not just the prescription or use of) high-intensity treatment, after modifiable factors and comorbidities have been appropriately managed. It includes two categories: 1) patients who maintain good control only while taking high-intensity treatment, in whom attempts to reduce therapy result in loss of control; and 2) patients with poor asthma control, frequent exacerbations and/or "brittle" asthma despite highintensity treatment. High-intensity treatment may be prompted by comorbidities that contribute to, or are interpreted as, poorly controlled asthma, and/or truly treatmentresistant asthma

and in level of treatment, it did not gain broad acceptance, perhaps because of its complexity. This may have been due to additional confusion arising from the use of the terms "intermittent", "mild persistent", "moderate persistent" and "severe persistent" to refer in turn to the patients' level of clinical control, their current treatment step, and their resulting severity classification.

Recent guidelines $[2,6]$ have reverted to a dual definition of asthma severity. For example, the EPR3 document [6] recommends that for clinical practice, severity should be defined on the basis of clinical features off-treatment. A second definition is included for use in population-based evaluations, clinical research or subsequent characterisation of the patient's overall severity, in which asthma severity would be inferred after optimal therapy was established, from the lowest level of treatment required to maintain control.

\section{IS A CONCEPT OF ASTHMA SEVERITY STILL NEEDED?}

Given that international asthma guidelines now agree that asthma management, first and foremost, should be based on the assessment of asthma control, is a concept of asthma severity still needed? If so, which of the preceding disparate concepts is most useful, and how can the accumulated confusion be resolved?

The most compelling argument for maintaining a concept of asthma severity is the widespread use in clinical practice of the expression "severe asthma" to refer to "difficult-to-treat" asthma. The expression "difficult to treat" has often been used $[9,10]$ to include not only patients in whom the process of asthma management is difficult (due to poor adherence, psychological problems and comorbidities contributing to cough, wheeze and the perception of dyspnoea, etc.), but also those who, although cooperative and adherent with their asthma management, require high-intensity treatment, with the attendant risk of treatment-related side-effects. Such patients consume a high proportion of asthma health resources, including the need for close monitoring [11], and there is active research interest in this problem. Several research networks have published criteria for defining severe asthma. The ENFUMOSA (European Network for Understanding Mechanisms of Severe Asthma) study group [12] defined severe asthma as the occurrence of one or more exacerbations in the previous year despite oral corticosteroids or high-dose ICS. The Severe Asthma Research Program, based in the USA, uses criteria established by an American Thoracic Society Workshop [9] to identify patients with persistent symptoms, asthma exacerbations or airway obstruction despite high medication use, in addition to those who require high medication doses in order to maintain good disease control. The TENOR (The Epidemiology and Natural History of Asthma: Outcomes and Treatment Regimens) study group [10] includes patients with high use of the healthcare system or high medication use in the past year. Taken together, despite some variation in their criteria, these definitions of severe asthma all incorporate a mandatory minimum criterion of high-dose anti-inflammatory treatment. Therefore, there is both clinical and research consensus that severe asthma is defined by the requirement for high-intensity treatment. It includes not only patients with poor control or frequent exacerbations despite high-intensity treatment, but also patients who can only maintain good control while taking high-intensity treatment (fig. 1). The requirement for highintensity treatment should be distinguished, on the one hand, from the prescription of high-intensity treatment (i.e. adherence should be taken into account) and, on the other hand, from mere use of high-intensity treatment, which in some patients may reflect over-treatment. Wherever possible, an attempt should be made to down-titrate treatment in order to assess optimum treatment requirements, before describing a patient as having severe asthma. Similarly, modifiable comorbidities should be addressed. Likewise, there are frequent references in clinical practice and in research publications to patients with mild asthma. Current usage indicates that these patients do not just have well-controlled asthma, but that they are able to be well-controlled with low-intensity treatment, such as low-dose ICS or leukotriene modifiers, or even with occasional short-acting $\beta_{2}$-agonist alone, i.e. they can be considered to have "easy-to-treat" asthma.

Hence, there is clinical utility in describing patients not only in relation to their level of asthma control, but also their asthma severity, in terms of the intensity of treatment required to treat the patient's asthma and to achieve good control [4]. Table 5 describes a classification of severity based on the lowest level of treatment required to achieve the patient's best level of control. It has been modified from the corresponding table in the EPR3 report, with medication class names rather than step numbers, in order to allow use with both the EPR3 treatment strategies (six steps) [6] and the GINA treatment strategies (five steps) [2]. There is a proviso: this system is based on the ranking of treatment intensity in current guidelines. Not all medications are available in all healthcare systems, and this may affect the assessment of asthma severity in some 


\begin{tabular}{ccccc} 
TABLE 5 Classification of asthma severity & Mild & Moderate & Severe \\
\hline $\begin{array}{c}\text { Intermittent } \\
\text { Lowest level of treatment } \\
\text { required to achieve patient's } \\
\text { best level of asthma control }\end{array}$ & SABA as needed & $\begin{array}{c}\text { Low-dose ICS or other low-intensity } \\
\text { treatment }(\text { e.g. cromolyn, LTRA, } \\
\text { nedocromil and theophylline) }\end{array}$ & $\begin{array}{c}\text { Low- to moderate-dose ICS } \\
\text { and LABA (or other extra } \\
\text { treatment) }^{\#}\end{array}$ & $\begin{array}{c}\text { High-intensity treatment (high-dose } \\
\text { ICS and LABA } \pm \text { oral corticoster- } \\
\text { oids and/or other extra treatment) }\end{array}$ \\
\hline
\end{tabular}

See also fig. 1. Modified from the Expert Panel Report 3 of the National Heart, Lung, and Blood Institute [6], with step numbers replaced by medication class names. Severity is based on the intensity of treatment required to control the patient's asthma once the diagnosis has been confirmed, comorbidities treated, and inhaler technique and adherence have been optimised. Down-titration should be performed, if possible, to avoid misclassification due to over-treatment. The description of treatment intensity is based on the medications and doses recommended in the stepwise treatment algorithm found in current guidelines [1,2]. It is acknowledged that not all of these medications will be available in all healthcare systems, and that this may affect the assessment of asthma severity in some environments. It is not yet known how new approaches, such as initial maintenance therapy with inhaled corticosteroids (ICS)/long-acting $\beta_{2}$-agonists (LABA), or maintenance and reliever therapy (e.g. with budesonide/formoterol), will be positioned in asthma guidelines, and hence how they will affect the classification of mild/moderate asthma. However, the same principle, of mild asthma being defined by the ability to achieve good control using very low-intensity treatment and severe asthma being defined by the requirement for high-intensity treatment, will still be applicable. SABA: short-acting $\beta_{2}$-agonist; LTRA: leukotriene receptor antagonist. ${ }^{*}$ : see guidelines for details [1, 2]

environments. Likewise, as guidelines about asthma treatment continue to evolve, there may be some modifications to this table over time. For example, the positioning in future guidelines of new approaches such as initial maintenance therapy with ICS/LABA, budesonide/formoterol as maintenance and reliever therapy, and phenotype-specific treatment, such as anti-immunoglobulin E, may influence severity assessment in the future. However, in principle, mild asthma would still be defined as the ability to achieve good control with very low-intensity treatment and severe asthma would still be defined by the need for high-intensity treatment.

Although long established, the additional concept of severity as the activity of the underlying disease off-treatment, as indicated by clinical features, has important limitations. It does not provide for easy assessment of change with time. It would be ethically inappropriate, after a period of treatment, to withdraw a patient's medications for 2-4 weeks to allow for reassessment of severity. Importantly, there is little research evidence that a patient's untreated state can consistently inform future management decisions. Identical clinical features may, in one patient, become completely controlled with lowdose ICS, while another patient may remain poorly controlled, despite high doses of multiple medications.

In summary, there is now broad support for the concept that "severity" ought to indicate the intensity of treatment required to treat a patient's asthma and there is little evidence to justify or retain a definition of severity as "disease activity offtreatment". It is confusing to have two different definitions of severity; the current authors recommend that the previous definition of asthma severity, i.e. clinical features off-treatment, should now be abandoned.

\section{ASTHMA SEVERITY, CONTROL AND PHENOTYPES}

Several reviews of the relationship between severity and control have been published [4, 13-16], although, not surprisingly, given the above history, the conclusions vary between authors. Most authors highlighted that the terms severity and control should not be regarded as synonymous, as patients with severe asthma may be well controlled on high doses of treatment and patients with mild asthma may be currently poorly controlled, e.g. owing to poor compliance. BATEMAN et al. [17] have shown that the probability of a patient becoming well controlled was independent of their baseline severity (defined by their baseline dose of ICS).

Although poor asthma control may be due to underlying severe disease or resistance to therapy, it is far more frequently due to poor compliance, poor inhaler technique, under-prescribing or environmental factors, such as allergen exposure or smoking. Patients may also appear to have poor clinical asthma control due to incorrect diagnosis and/or significant comorbidities. By the American Thoracic Society Workshop definition [9], before a label of severe asthma can be applied, other diagnoses or comorbidities must be excluded, exacerbating factors treated and the patient must be generally adherent. This avoids classifying patients with poor asthma control as having severe asthma if they are, in fact, misdiagnosed or have readily treatable but essentially under-treated asthma. However, some patients may continue to require high-intensity asthma treatment (and hence be defined as having severe asthma) because of persistent symptoms owing to conditions such as rhinosinusitis, reflux or psychosocial problems, despite the best available management strategies for these conditions. These often give rise to symptoms of cough, wheeze or dyspnoea in their own right, leading to a perception, both by patients and the clinician, that asthma is severe and/or poorly controlled. Comorbidities may also potentially have a direct effect on airway inflammation. Likewise, other patients may require intensive intervention on an ongoing basis because of residual problems, such as allergen exposure or persistently poor compliance, despite appropriate interventions (fig. 1).

More recently, there has been increasing awareness of heterogeneity of the underlying disease processes in asthma. Recent reviews have highlighted the importance of different asthma phenotypes, their natural history and varying treatment responses [18, 19]. These phenotypes may alter the intensity of the treatment required (severity) and, in turn, contribute to the patient's level of asthma control. Figure 2 shows the current perspective on the relationships between phenotype, severity and control. 


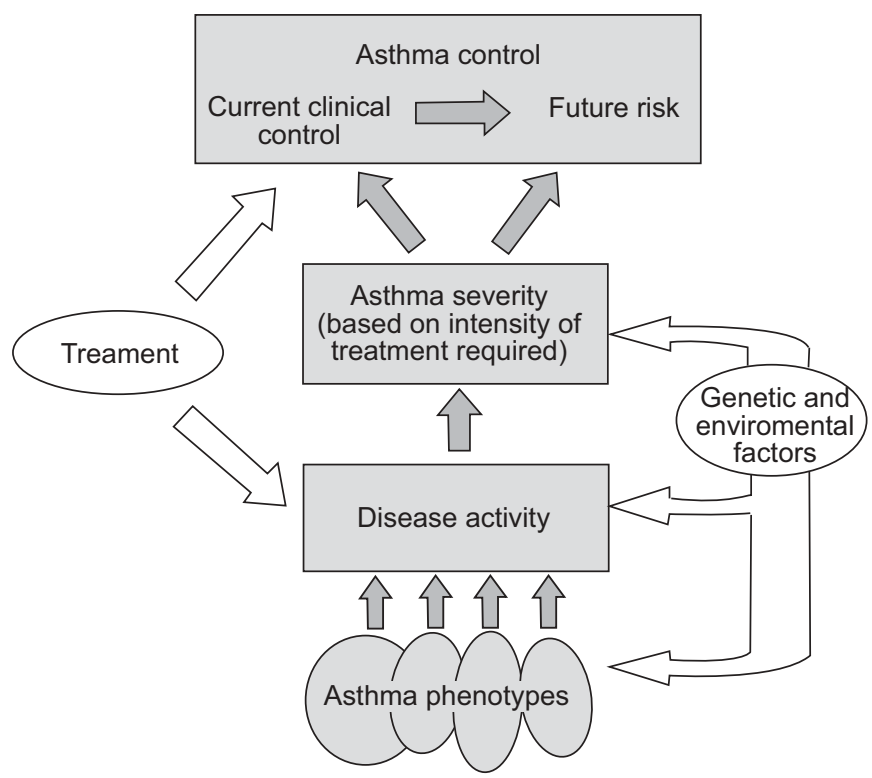

FIGURE 2. Relationship between asthma phenotype, severity and control. The level of asthma control results from the interaction of the underlying phenotype, the environment (genetic and external) and the response to treatment. The assessment of asthma control has two components: current clinical control (including symptoms, reliever use and simple "bedside" measures of lung function) and future risk of adverse outcomes (e.g. exacerbations, rapid decline in lung function, and side-effects). Treatment choice may be governed by the underlying phenotype, and the intensity of treatment is usually modified by the clinician as the patient responds to treatment. Severity is described by the intensity of the treatment required to achieve good control. Severe asthma includes situations in which good control is still not achieved despite maximal therapy. Pathological and physiological markers provide information about the underlying phenotype and the level of residual disease activity on treatment and may serve as surrogate markers for future risk. Exacerbations are events that are more common in poorly controlled asthma but may occur at any level of clinical asthma control.

Although it has been affirmed that asthma severity and control are distinct entities, they have a close interrelationship, which is clearly dynamic and changes over time, as well as with treatment [20]. Severity, defined by the intensity of the required treatment, is a relatively stable feature which, in the context of the stepwise asthma management approach described in current guidelines [1, 2], changes only slowly over time. In contrast, the level of asthma control may vary from day to day or week to week with changes in environmental triggers or treatment adherence.

One of the complicating issues in this discussion arises from the fact that, although exacerbations are a prominent feature of both severe and poorly controlled asthma, they may be equally experienced by patients with any level of asthma severity or control. Severe asthma exacerbations may occur in patients with newly diagnosed [21] or well-controlled [22] asthma or even by atopic patients with no previous asthma symptoms [23]. Exacerbations, by definition and in clinical practice, are identified by a change from and return to previous status, i.e. by their time trend. Unless this is taken into account, exacerbations may be indistinguishable from poorly controlled asthma if only cross-sectional analysis of clinical features, such as symptoms and static lung function, are considered [22].

\section{IS THE ASSESSMENT OF CLINICAL ASTHMA CONTROL SUFFICIENT?}

Basing treatment decisions on the patient's current level of clinical asthma control $[2,6]$ recognises the importance of the patient's perspective and is a pragmatic approach accessible to all clinicians. Substantial improvements in asthma control and in health status have been achieved in studies using clinical algorithms in which features of asthma control are the basis for an increase [24] or decrease [8] in medications. Clinicians are often reluctant to reduce treatment, even when asthma is wellcontrolled [25], but patients appear ready to do this themselves by reducing their adherence when symptoms improve [26, 27].

So, if it is simple and apparently effective to base treatment decisions on clinical asthma control, does the assessment of current control alone provide sufficient information for optimal decisions about asthma management? The current authors do not believe so. Information, other than just "treatment step", is clearly necessary in order to describe the underlying phenotype and current disease activity on treatment. For example, biomarkers from induced sputum may be used to characterise the asthma phenotype according to the extent and type of airway inflammation. Characterisation of patients' phenotype will become increasingly important in the development of targeted therapies, as some patients who were previously classified as having severe asthma because of poor asthma control despite maximal ICS/LABA therapy may become well-controlled with a targeted phenotype-specific treatment, e.g. anti-neutrophilic therapy. The fact that, at a group level, pathophysiological markers, such as sputum eosinophils and AHR, do not necessarily correlate strongly with one another or with patients' clinical features [28] also suggests that they add independent information about a patient's underlying phenotype and severity. It appears unlikely that a single pathophysiological marker will be suitable for the assessment of asthma in all patients and for all medications.

Phenotypic/pathophysiological markers are not only useful for characterising populations, but can provide information relevant to treatment decisions, additional to that obtained from assessing current clinical control. For example, the use of LABA alone may offer false reassurance by improving symptoms, morning PEF $[29,30]$ and even composite control scores [30] but, because they do not treat the underlying disease process, they expose the patient to a greater risk of exacerbations [29]. In addition, several pathological and physiological markers have been shown to predict future risk of exacerbations [31-37] or loss of lung function [38, 39] independently of features of clinical control. Furthermore, treatment algorithms based on AHR [40], sputum eosinophils $[41,42]$ or exhaled nitric oxide $[43,44]$ have shown benefit in terms of reduced exacerbations and/or reduced medication requirements, when compared with, or added to, algorithms based on the assessment of current clinical control.

\section{HOW SHOULD CLINICAL ASTHMA CONTROL BE DEFINED AND ASSESSED?}

Formal recommendations from the Task Force about specific outcome variables that should be used for the assessment of asthma control will be published in due course. Current clinical control is assessed by direct observation of the patient's current or recent clinical status on treatment. Optimum or 
complete control implies that the patient is free from daily symptoms and exacerbations, variability in lung function is minimised, and quality of life is unimpaired. The most important viewpoint is that of the patient, but when patients are asked how well their asthma is controlled, the responses may differ substantially from those obtained using guidelinebased measures [45]. This does not necessarily imply that patients are prepared to accept less than optimal asthma control, but may merely be due to patients having a different interpretation of the word "control" from that in current medical usage (just as a trauma patient's assessment of whether they were "shocked" might differ from that of an Emergency Department physician) [46]. Alternatively, the patient's perspective of what constitutes "ideal" control may reflect a personal balance of priorities between clinical benefits and real or perceived risks (including side-effects and the cost of treatment) [27].

The terminology that has been used to describe asthma control is problematic. The expression "asthma control" has been used to refer not only to the whole continuum from poor control to good control (as in "assessing asthma control"), but also to one end of that continuum (as in "achieving control"). Terms such as "good" and "poor", or "controlled" and "uncontrolled" represent categorical classifications, which require agreement regarding the threshold criteria. Whether it is frequency of night waking, puffs of reliever medication or morning peak flows, setting cut points with the intention of distinguishing between, for example, optimal, suboptimal and poor control, poses significant challenges and scope for disagreement [20]. Hence, most of the individual features of asthma control are better represented as continuous rather than categorical variables. The levels of control that are regarded as acceptable or satisfactory may also vary depending on the perspective; be it that of patient, clinician or researcher.

In the past, guidelines have specified that one feature (the patient's worst feature) should define his/her level of control. Conversely, all component variables are required to satisfy pre-determined criteria for good or total control. Given the poor specificity of asthma symptoms, this approach may potentially lead to over-treatment. As the number of criteria for good control increases, or as the period of time over which each assessment of control is based increases, the proportion of patients who will be categorised as having good control will decrease [47], so it is important to standardise both the number of criteria and the duration of assessment. This has not been done consistently in the past.

Current guidelines [2] identify the goals of asthma treatment as the achievement of good asthma control and reduction of future risk to the patient, with minimum cost and side-effects. Achievement of good clinical control is itself associated with reduced risk of future exacerbations and reduced healthcare costs [48, 49]. However, measuring biomarkers that reflect underlying airway inflammation and hyperresponsiveness may provide additional information about future risk of exacerbations and about a patient's likely response to treatment and, if they demonstrate responsiveness to treatment over a short to medium time frame, they may help to guide decisions about treatment. They provide a link between the phenotype, severity and control.

\section{CONCLUSIONS}

The terms "severity" and "control" refer to distinct entities which nonetheless represent overlapping dimensions of the asthma syndrome. They are not synonymous and ought not to be used interchangeably.

The current authors recommend that the term "severity" should be used to refer to the intensity of treatment required to control the patient's asthma. This may be determined by the patient's underlying phenotype. Measurement of pathophysiological markers may help to characterise the phenotype and provide additional information about future risk of adverse outcomes. The concept of severity as clinical features offtreatment should be abandoned.

"Asthma control" refers to the extent to which the manifestations of asthma have been reduced or removed by treatment. Its assessment should incorporate the dual components of current clinical control (e.g. symptoms, reliever use and clinic lung function) and future risk (e.g. exacerbations and rapid decline in lung function). Asthma control is of key importance to patients, with regard to both their current status and their risk of future adverse outcomes.

\section{ACKNOWLEDGEMENTS}

Author affiliations are as follows: D.R. Taylor: Dunedin School of Medicine, University of Otago, Dunedin, New Zealand; E.D. Bateman: University of Cape Town Lung Institute, Cape Town, South Africa; L-P. Boulet: Institut de Cardiologie et de Pneumologie de l'Hôpital Laval, Québec, QC, Canada; H.A. Boushey and S.C. Lazarus: University of California, San Francisco, CA, USA; W.W. Busse: University of Wisconsin, Madison, WI, USA; T.B. Casale: Creighton University, Omaha, NE, USA; P. Chanez: Université de la Méditerranée, Marseille, France; P.L. Enright: University of Arizona, Tucson, AZ, USA; P.G. Gibson: Centre for Asthma \& Respiratory Disease and Hunter Medical Research Institute, University of Newcastle, Newcastle, Australia; J.C. de Jongste: Sophia Childrens' Hospital, Rotterdam, The Netherlands; H.A.M. Kerstjens: University Medical Center, Groningen, The Netherlands; M.L. Levy: University of Edinburgh, Edinburgh, UK; P.M. O'Byrne and M.R. Sears: Firestone Institute for Respiratory Health, Hamilton, ON, Canada; M.R. Partridge: Imperial College, London, UK; I.D. Pavord: Glenfield Hospital, University Hospitals of Leicester NHS Trust, Leicester, UK; P.J. Sterk: University of Amsterdam, Amsterdam, The Netherlands; S.W. Stoloff: University of Nevada School of Medicine, Reno, NV, USA; S.J. Szefler: National Jewish Medical and Research Center and University of Colorado Health Sciences Center, Denver, CO, USA; S.D. Sullivan: University of Washington, Seattle, WA, USA; M.D. Thomas: University of Aberdeen, Aberdeen, UK; S.E. Wenzel: University of Pittsburgh, Pittsburgh, PA, USA; H.K. Reddel: Woolcock Institute of Medical Research, Camperdown, Australia.

\section{REFERENCES}

1 National Asthma Education and Prevention Program Expert Panel Report 2. Guidelines for the Diagnosis and Management of Asthma. Bethesda, National Heart, Lung, and Blood Institute, 1997. 
2 Global Initiative for Asthma. Global strategy for asthma management and prevention 2006. Available from www.ginasthma.com Date last accessed: August 2007.

3 Global Initiative for Asthma. Asthma Management and Prevention. NIH Publication number 95-3659A. Bethesda, National Institutes of Health, 1995.

4 Cockcroft DW, Swystun VA. Asthma control versus asthma severity. J Allergy Clin Immunol 1996; 98: 1016-1018.

5 National Heart, Lung, and Blood Institute. International consensus report on diagnosis and treatment of asthma. Eur Respir J 1992; 5: 601-641.

6 National Heart, Lung, and Blood Institute. National Asthma Education and Prevention Program. Expert Panel Report 3: Guidelines for the Diagnosis and Management of Asthma 2007. www.nhlbi.nih.gov/guidelines/asthma/ asthgdln.htm Date last accessed: September 2007.

7 Global Initiative for Asthma. Workshop Report. Global strategy for asthma management and prevention 2002.

8 Reddel HK, Jenkins CR, Marks GB, et al. Optimal asthma control, starting with high doses of inhaled budesonide. Eur Respir J 2000; 16: 226-235.

9 American Thoracic Society. Proceedings of the ATS workshop on refractory asthma: current understanding, recommendations, and unanswered questions. Am J Respir Crit Care Med 2000; 162: 2341-2351.

10 Dolan CM, Fraher KE, Bleecker ER, et al. Design and baseline characteristics of the epidemiology and natural history of asthma: Outcomes and Treatment Regimens (TENOR) study: a large cohort of patients with severe or difficult-to-treat asthma. Ann Allergy Asthma Immunol 2004; 92: 32-39.

11 Sullivan SD, Rasouliyan L, Russo PA, Kamath T, Chipps BE, Group TS. Extent, patterns, and burden of uncontrolled disease in severe or difficult-to-treat asthma. Allergy 2007; 62: 126-133.

12 The ENFUMOSA cross-sectional European multicentre study of the clinical phenotype of chronic severe asthma. European Network for Understanding Mechanisms of Severe Asthma. Eur Respir J 2003; 22: 470-477.

13 Osborne ML, Vollmer WM, Pedula KL, Wilkins J, Buist AS, O'Hollaren M. Lack of correlation of symptoms with specialist-assessed long-term asthma severity. Chest 1999; 115: 85-91.

14 Fuhlbrigge AL. Asthma severity and asthma control: symptoms, pulmonary function, and inflammatory markers. Curr Opin Pulm Med 2004; 10: 1-6.

15 Vollmer WM. Assessment of asthma control and severity. Ann Allergy Asthma Immunol 2004; 93: 409-413.

16 Stoloff SW, Boushey HA. Severity, control, and responsiveness in asthma. J Allergy Clin Immunol 2006; 117: 544-548.

17 Bateman ED, Bousquet J, Braunstein GL. Is overall asthma control being achieved? A hypothesis-generating study. Eur Respir J 2001; 17: 589-595.

18 Bel EH. Clinical phenotypes of asthma. Curr Opin Pulm Med 2004; 10: 44-50.

19 Wenzel SE. Asthma: defining of the persistent adult phenotypes. Lancet 2006; 368: 804-813.

20 Combescure C, Chanez P, Saint-Pierre P, et al. Assessment of variations in control of asthma over time. Eur Respir J 2003; 22: 298-304.
21 Pauwels RA, Pedersen S, Busse WW, et al. Early intervention with budesonide in mild persistent asthma: a randomised, double-blind trial. Lancet 2003; 361: 1071-1076.

22 Reddel H, Ware S, Marks G, Salome C, Jenkins C, Woolcock A. Differences between asthma exacerbations and poor asthma control. Lancet 1999; 353: 364-369.

23 Girgis ST, Marks GB, Downs SH, Kolbe A, Car GN, Paton R. Thunderstorm-associated asthma in an inland town in south-eastern Australia. Who is at risk? Eur Respir J 2000; 16: 3-8.

24 Bateman ED, Boushey HA, Bousquet J, et al. Can guidelinedefined asthma control be achieved? The Gaining Optimal Asthma ControL study. Am J Respir Crit Care Med 2004; 170: 836-844.

25 Diette GB, Patino CM, Merriman B, et al. Patient factors that physicians use to assign asthma treatment. Arch Intern Med 2007; 167: 1360-1366.

26 Ulrik C, Backer V, Soes-Petersen U, Lange P, Harving H, Plaschke P. The patient's perspective: adherence or nonadherence to asthma controller therapy? J Asthma 2006; 43: 701-704.

27 Horne R, Price D, Cleland J, et al. Can asthma control be improved by understanding the patient's perspective? BMC Pulmonary Medicine 2007; 7: 8.

28 Rosi E, Ronchi MC, Grazzini M, Duranti R, Scano G. Sputum analysis, bronchial hyperresponsiveness, and airway function in asthma: results of a factor analysis. J Allergy Clin Immunol 1999; 103: 232-237.

29 Lazarus SC, Boushey HA, Fahy JV, et al. Long-acting B2agonist monotherapy versus continued therapy with inhaled corticosteroids in patients with persistent asthma: a randomized controlled trial. JAMA 2001; 285: 2583-2593.

30 Jenkins CR, Thien FCK, Wheatley JR, Reddel HK. Traditional and patient-centred outcomes with three classes of asthma medication. Eur Respir J 2005; 26: 36-44.

31 Ulrik CS, Frederiksen J. Mortality and markers of risk of asthma death among 1,075 outpatients with asthma. Chest 1995; 108: 10-15.

32 Leuppi JD, Salome CM, Jenkins CR, et al. Predictive markers of asthma exacerbation during stepwise dose reduction of inhaled corticosteroids. Am J Respir Crit Care Med 2001; 163: 406-412.

33 Fuhlbrigge AL, Kitch BT, Paltiel AD, et al. FEV1 is associated with risk of asthma attacks in a paediatric population. J Allergy Clin Immunol 2001; 107: 61-67.

34 Harkins MS, Fiato KL, Iwamoto GK. Exhaled nitric oxide predicts asthma exacerbation. J Asthma 2004; 41: 471-476.

35 Kitch BT, Paltiel AD, Kuntz KM, et al. A single measure of FEV1 is associated with risk of asthma attacks in long-term follow-up. Chest 2004; 126: 1875-1882.

36 Frey U, Brodbeck T, Majumdar A, et al. Risk of severe asthma episodes predicted from fluctuation analysis of airway function. Nature 2005; 438: 667-670.

37 Osborne ML, Pedula KL, O'Hollaren M, et al. Assessing future need for acute care in adult asthmatics: The Profile of Asthma Risk (PAR) Study. A prospective health maintenance organization-based study. Chest 2007; 132: 1151-1161.

38 Ulrik CS. Outcome of asthma: longitudinal changes in lung function. Eur Respir J 1999; 13: 904-918. 
39 Ten Brinke A, Zwinderman AH, Sterk PJ, Rabe KF, Bel EH. Factors associated with persistent airflow limitation in severe asthma. Am J Respir Crit Care Med 2001; 164: 744-748.

40 Sont JK, Willems LN, Bel EH, van Krieken JH, Vandenbroucke JP, Sterk PJ. Clinical control and histopathologic outcome of asthma when using airway hyperresponsiveness as an additional guide to long-term treatment. The AMPUL Study Group. Am J Respir Crit Care Med 1999; 159: 1043-1051.

41 Green RH, Brightling CE, McKenna S, et al. Asthma exacerbations and sputum eosinophil counts: a randomised controlled trial. Lancet 2002; 360: 1715-1721.

42 Jayaram L, Pizzichini MM, Cook RJ, et al. Determining asthma treatment by monitoring sputum cell counts: effect on exacerbations. Eur Respir J 2006; 27: 483-494.

43 Smith AD, Cowan JO, Brassett KP, Herbison GP, Taylor DR. Use of exhaled nitric oxide measurements to guide treatment in chronic asthma. N Engl J Med 2005; 352: 2163-2173.

44 Pijnenburg MW, Bakker EM, Hop WC, De Jongste JC. Titrating steroids on exhaled nitric oxide in children with asthma: a randomized controlled trial. Am J Respir Crit Care Med 2005; 172: 831-836.

45 Rabe KF, Adachi M, Lai CKW, et al. Worldwide severity and control of asthma in children and adults. The global Asthma Insights and Reality surveys. J Allergy Clin Immunol 2004; 114: 40-47.

46 Marks GB, Abramson MJ, Jenkins CR, et al. Asthma management and outcomes in Australia: a nation-wide telephone interview survey. Respirology 2007; 12: 212-219.

47 Fuhlbrigge AL, Adams RJ, Guilbert TW, et al. The burden of asthma in the United States: level and distribution are dependent on interpretation of the national asthma education and prevention program guidelines. Am J Respir Crit Care Med 2002; 166: 1044-1049.

48 Briggs $\mathrm{AH}$, Bousquet J, Wallace MV, et al. Cost-effectiveness of asthma control: an economic appraisal of the GOAL study. Allergy 2006; 61: 531-536.

49 Sullivan SD, Wenzel SE, Bresnahan BW, et al. Association of control and risk of severe asthma-related events in severe or difficult-to-treat asthma patients. Allergy 2007; 62: 655-660. 